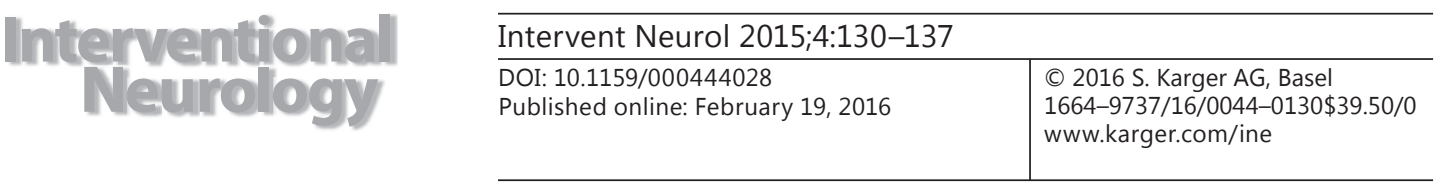

\title{
Symptomatic Infratentorial Thrombosed Developmental Venous Anomaly: Case Report and Review of the Literature
}

\author{
Krishna Amuluru ${ }^{a}$ Fawaz Al-Mufti ${ }^{a}$ Stephen Hannaford ${ }^{a}$ \\ Inder Paul Singh ${ }^{a, b} \quad$ Charles J. Prestigiacomo ${ }^{a-c}$ Chirag D. Gandhi ${ }^{a-c}$ \\ Departments of a Neurosurgery and Neuroscience, ${ }^{b}$ Neurology and ${ }^{c}$ Radiology, Rutgers \\ University School of Medicine, Newark, N.J., USA
}

\section{Key Words}

Cerebral venous thrombosis - Developmental venous anomaly · Diagnostic cerebral angiography $\cdot$ Magnetic resonance imaging $\cdot$ Venous angioma

\begin{abstract}
Background: Developmental venous anomalies (DVAs) are variations of normal transmedullary veins draining white and gray matter. In the vast majority of cases, DVAs are diagnosed incidentally and should be considered as benign entities. In extremely rare circumstances, DVAs may become symptomatic due to mechanical or flow-related etiologies. Thrombosis of the collector vein of a DVA is a rare type of a flow-related complication with only 29 cases reported in the literature, the majority of which are supratentorial. Infratentorial thrombosed DVAs are thus extremely rare and the few cases reported have typically caused symptoms due to venous ischemic infarctions. Summary: We report a case of an infratentorial DVA with a thrombosed drainage vein in a patient with nonhemorrhagic, noninfarcted venous congestive edema, which was successfully treated with high-dose glucocorticoids and short-term anticoagulation. We review the pertinent venous anatomy of the posterior fossa as well as the literature of symptomatic infratentorial thrombosed DVAs. Key Message: The presented case of an infratentorial thrombosed DVA with cerebellar and pontine venous congestive edema is extremely rare. A working knowledge of posterior fossa venous anatomy and possible pathomechanisms responsible for the rarely symptomatic lesion will aid in the timely and efficacious treatment of such lesions.

(c) 2016 S. Karger AG, Basel
\end{abstract}




\section{Introduction}

Developmental venous anomalies (DVAs) are variants of habitual transmedullary veins that provide normal drainage of brain parenchyma. Once believed to pose a high risk for hemorrhage, pseudotumoral symptoms and seizures, DVAs are now considered to be predominantly asymptomatic, and are a frequent incidental finding on radiological and autopsy series [1]. DVAs are most often located supratentorially, with only $14-29 \%$ occurring in the cerebellum, and just $5 \%$ involving the brainstem $[2,3]$.

Symptomatic cases represent a rare subset of DVAs and patients may present with headaches, seizures, focal neurological deficits, dizziness and ataxia [1, 2]. Symptoms may be secondary to mechanical compression of adjacent intracranial structures (e.g., hydrocephalus or nerve compression) or flow-related pathomechanisms, such as restriction of the venous outflow [4].

Symptomatic outflow restriction of a DVA can be caused by stenosis or thrombosis of the collection system [2]. Drainage vein thrombosis of a DVA is rare, and only 29 cases of symptomatic thrombosed DVAs have been reported in the literature. Of these 29 cases, only 8 have been infratentorial [1-3,5-9], and only 1 of those cases was due to venous congestion without subsequent venous infarction or hemorrhage (table 1). Thus, to the best of our knowledge, we present only the second case of an infratentorial thrombosed DVA causing venous congestive edema without concurrent infarction or hemorrhage.

\section{Case Presentation}

A 53-year-old woman with a history of spina bifida presented to the emergency department with 3 days of headache, nausea, vomiting, and impaired ambulation. The patient also complained of vertigo that was exacerbated by lateral head movements. Her vital signs were all within normal ranges. On physical exam, she demonstrated left upper extremity dysmetria and an ataxic gait. The remainder of the exam was

Table 1. Reported cases of infratentorial thrombosed DVAs

\begin{tabular}{|c|c|c|c|c|c|c|}
\hline Case & Reference & DVA location & Presentation & Morphology & Management & Outcome \\
\hline 1 & $\begin{array}{l}\text { Agarwal et al. [7], } \\
\text { (2014) }\end{array}$ & Left cerebellum & $\begin{array}{l}\text { Headache, ataxia, } \\
\text { syncope }\end{array}$ & $\begin{array}{l}\text { Venous ischemic } \\
\text { infarct }\end{array}$ & Anticoagulation & Residual ataxia \\
\hline 2 & $\begin{array}{l}\text { Griffiths et al. [9], } \\
\text { (2013) }\end{array}$ & Right pons & $\begin{array}{l}\text { Headache, dysarthria, } \\
\text { ataxia }\end{array}$ & $\begin{array}{l}\text { Venous ischemic } \\
\text { infarct, petechial } \\
\text { hemorrhage }\end{array}$ & Anticoagulation & Complete resolution \\
\hline 3 & $\begin{array}{l}\text { Kiroglu et al. [8], } \\
\text { (2011) }\end{array}$ & Left cerebellum & $\begin{array}{l}\text { Headache, dizziness, } \\
\text { syncope }\end{array}$ & $\begin{array}{l}\text { Venous ischemic } \\
\text { infarct }\end{array}$ & $\begin{array}{l}\text { Ventricular shunt, urgent } \\
\text { occipital decompression, } \\
\text { anticoagulation }\end{array}$ & $\begin{array}{l}\text { Residual ataxia, } \\
\text { dysmetria }\end{array}$ \\
\hline 4 & $\begin{array}{l}\text { Pereira et al. [2], } \\
\text { (pt 4) (2008) }\end{array}$ & Cerebellum & $\begin{array}{l}\text { Headache, Parinaud } \\
\text { syndrome }\end{array}$ & $\begin{array}{l}\text { Venous } \\
\text { congestion }\end{array}$ & Conservative & $\begin{array}{l}\text { Spontaneous } \\
\text { recovery }\end{array}$ \\
\hline 5 & $\begin{array}{l}\text { Peltier et al. [1], } \\
(2004)\end{array}$ & Left cerebellum & $\begin{array}{l}\text { Headache, vomiting, } \\
\text { coma }\end{array}$ & $\begin{array}{l}\text { Venous ischemic } \\
\text { infarct }\end{array}$ & $\begin{array}{l}\text { Conservative, ventricular } \\
\text { drain for hydrocephalus }\end{array}$ & $\begin{array}{l}\text { Recovery with mild } \\
\text { symptoms }\end{array}$ \\
\hline 6 & $\begin{array}{l}\text { Lovrencic-Huzjan } \\
\text { et al. [6], (2004) }\end{array}$ & Inferior vermis & Headache, stiff neck & $\begin{array}{l}\text { Subarachnoid } \\
\text { hemorrhage }\end{array}$ & Conservative & Complete resolution \\
\hline 7 & $\begin{array}{l}\text { Konan et al. [5], } \\
\text { (1999) }\end{array}$ & $\begin{array}{l}\text { Bilateral } \\
\text { cerebellum }\end{array}$ & $\begin{array}{l}\text { Vomiting, ataxia, } \\
\text { followed by coma }\end{array}$ & $\begin{array}{l}\text { Venous ischemic } \\
\text { infarct }\end{array}$ & $\begin{array}{l}\text { Conservative, ventricular } \\
\text { shunt for hydrocephalus }\end{array}$ & $\begin{array}{l}\text { Independent, with } \\
\text { ataxia and right } \\
\text { facial nerve palsy }\end{array}$ \\
\hline 8 & $\begin{array}{l}\text { Guerrero et al. } \\
\text { [3], (1998) }\end{array}$ & Right cerebellum & $\begin{array}{l}\text { Headache, diplopia, } \\
\text { ataxia and vertigo }\end{array}$ & $\begin{array}{l}\text { Venous ischemic } \\
\text { infarct }\end{array}$ & Conservative & Mild recovery \\
\hline
\end{tabular}


Fig. 1. a Axial noncontrast CT scan demonstrates hyperdense linear structure transversing the left middle cerebellar peduncle extending into the left cerebellopontine angle cistern. Brain MRI (b-f): axial 3D SWAN image (b) shows susceptibility indicating intraluminal thrombus; T2weighted axial (c) and coronal (d) sequences show edema within the left side of the pons extending caudally into the brachium pontis surrounding a flow void representing the collector vein. Gadolinium-enhanced T1-weighted fat-saturated axial images (e-f) show multiple enhancing medullary veins, with caput medusa appearance (e; open arrow), within the left cerebellum. Subtle parenchymal contrast enhancement surrounding the medullary veins (arrowheads) suggests restriction of venous outflow. Focus of nonenhancement (f; arrow) indicates thrombosed draining vein.

Amuluru et al.: Symptomatic Infratentorial Thrombosed Developmental Venous Anomaly: Case Report and Review of the Literature

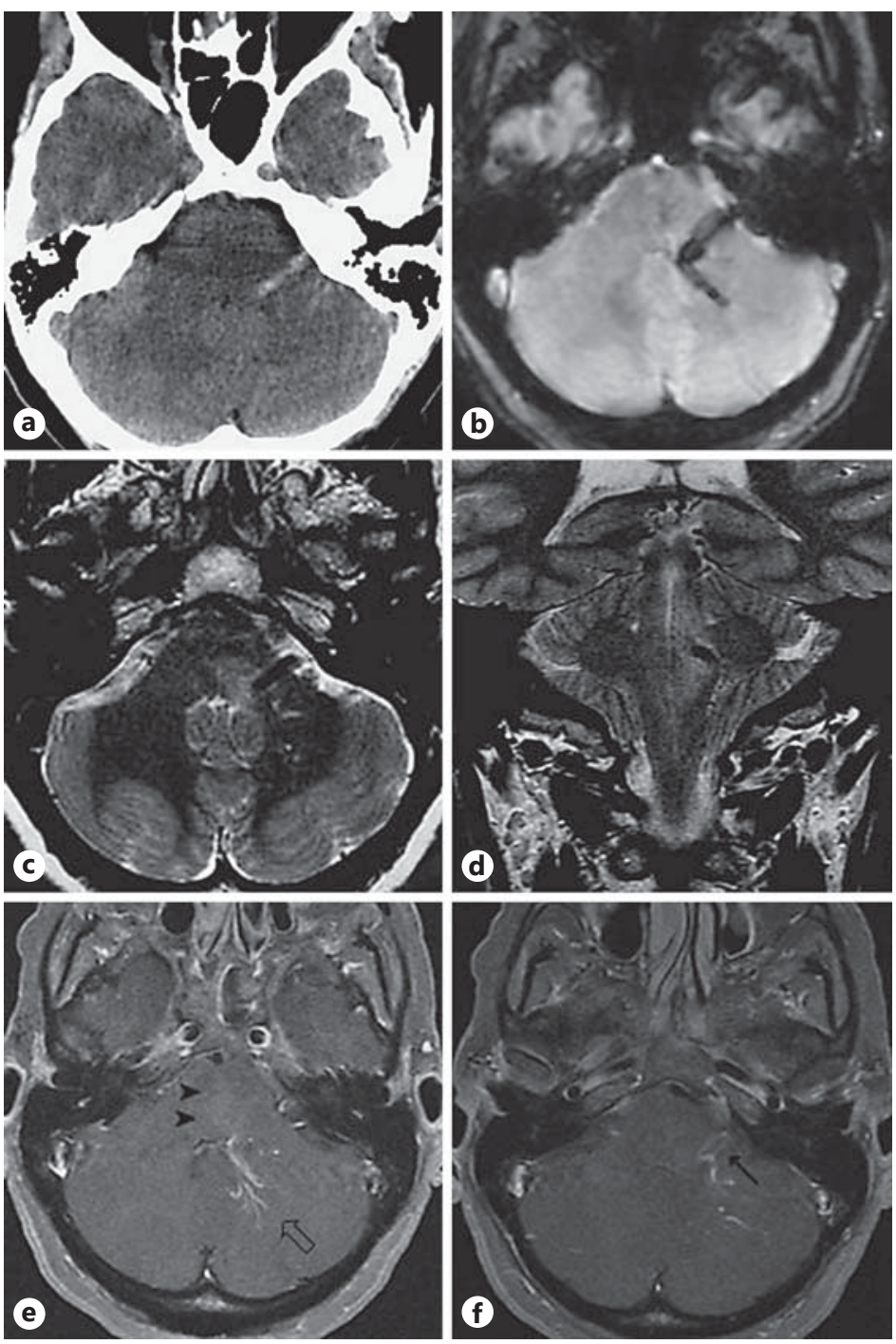

otherwise normal including normal cranial nerve function and cerebellar testing. Laboratory tests including complete blood count, basic metabolic panel, hepatic metabolic panel, urinalysis, and urine toxicity were normal.

Noncontrast computed tomography (CT) of the head showed no acute hemorrhage or hydrocephalus, though a hyperdense curvilinear structure was identified in the left cerebellopontine angle cistern (fig. 1a) for which magnetic resonance imaging (MRI) was recommended. MRI of the brain showed abnormal T2 signal in the dorsal pons extending caudally to the left brachium pontis, inferomedial left cerebellar hemisphere and dorsal medulla (fig. 1c, d). There was no restricted diffusion on diffusion-weighted images, nor was there parenchymal hypointensity on gradient echo $\mathrm{T} 2 *$-weighted images to suggest acute or chronic hemorrhage. Axial 3D SWAN images (fig. 1b) showed small tubular structures within the dorsal pons and inferior left cerebellum converging on a hypointense curvilinear structure traversing the inferior left brachium pontis consistent with intraluminal thrombus (intracellular methemoglobin). Gadoliniumenhanced T1-weighted fat-saturated images showed 'caput medusae' enhancement of the left cerebellar medullary veins, as well as nonenhancement of a segment of the collector vein (fig. 1e, f). No other vascular malformations were identified. The differential diagnosis included arteriovenous malformation (AVM), dural arteriovenous (AV) fistula with thrombosis, or thrombosed developmental venous anomaly causing venous congestive edema. Diagnostic cerebral angiogram confirmed the presence of a DVA (fig. 2a), while conforming the intraluminal thrombus (fig. 2b) and excluding both AVM and dural AV fistula. 
Amuluru et al.: Symptomatic Infratentorial Thrombosed Developmental Venous Anomaly: Case Report and Review of the Literature

Fig. 2. a Mid-venous phase of left vertebral artery digital subtraction angiogram in anteroposterior view shows caput medusa appearance of medullary veins (arrows). b Mid-venous phase in oblique view shows filling defect of intraluminal thrombus within the vein of the lateral recess (open arrow). Note arterial mask of basilar artery and cerebellomesencephalic segment of left superior cerebellar artery localizing the thrombus adjacent to cerebellar peduncle.
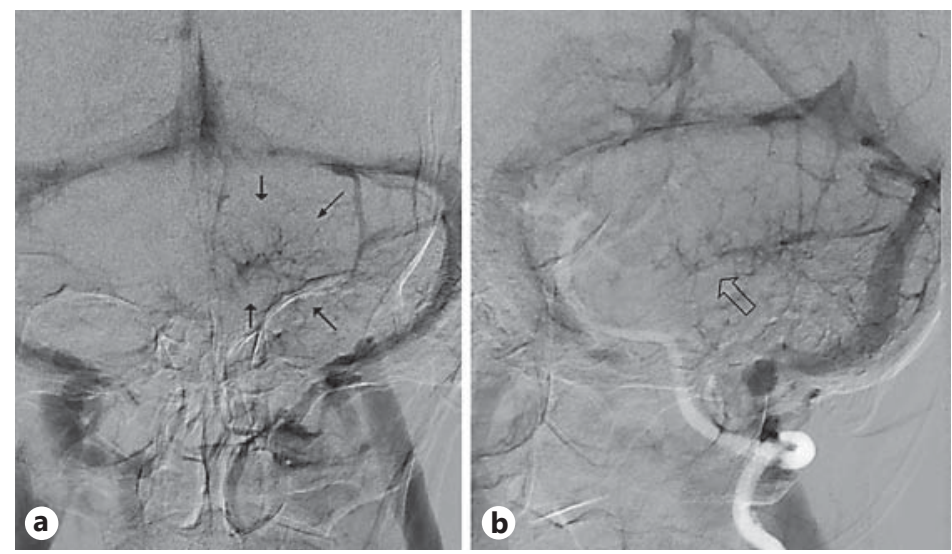

Fig. 3. Three-month follow-up MRI. T2-weighted axial (a) and coronal (b) sequences showing complete resolution of venous congestive edema and return to normal caliber of the collector vein.
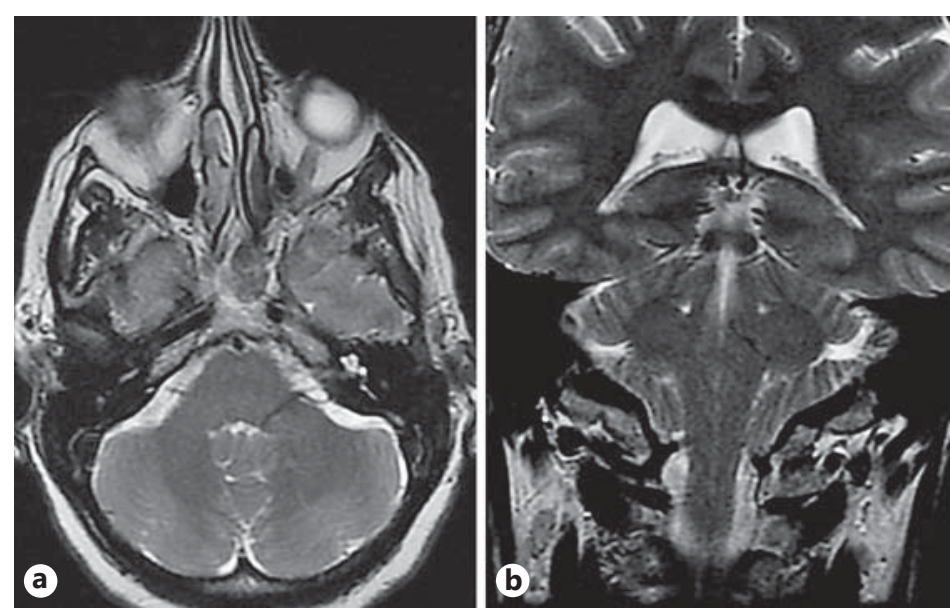

A hypercoaguable workup including antithrombin III, protein C, and protein S levels was negative. There was no activated protein $\mathrm{C}$ resistance or factor $\mathrm{V}$ Leiden mutation. Antiphospholipid antibodies were not detected. The patient was started on high-dose steroids, which led to resolution of her headache, cessation of nausea and vomiting, and improvement in ambulation. In the absence of an associated cavernous malformation, anticoagulation therapy was initiated. At the time of discharge, her symptoms were nearly resolved, and she was continued on steroids and 8 weeks of anticoagulation. At both a 3- and 7-month follow-up visit, the patient was asymptomatic, and MRI showed complete resolution of the posterior fossa edema, and resolution of the susceptibility artifact within the DVA (fig. 3).

\section{Discussion}

DVAs are variations of normal transmedullary veins draining white and gray matter, and have a reported incidence between 0.7 and $2.6 \%[8,10,11]$. They are characterized by a network of thin-walled, dilated transmedullary veins draining into a large collector vein, which lacks a smooth muscle layer and elastic lamina $[2,8]$. Transmedullary and collector veins of the DVA can involve any portion of the forebrain, midbrain, or hindbrain. Classification is based on the drainage pattern of the collector vein, which may empty into the deep subependymal veins and/or vein of Galen, the superficial subcortical veins, or both.

DVAs are often incidentally identified by curvilinear enhancement of the venous collector on contrast-enhanced CT. In the present case, a curvilinear hyperdensity on the initial noncon- 
trast CT scan identified the thrombosed collector vein. The standard imaging modality for DVAs is MRI. Restricted flow through the DVA results in a flow void on T1- and T2-weighted images; thus, administration of gadolinium is necessary for enhancement of the medullary veins and visualization of the drainage route of the venous collector. Classical angiographic appearance is that of a 'caput medusa' appearance of transmedullary veins during the early to middle venous phase, draining into a large venous collector, which can extend to either the superficial or deep venous system [2]. Diagnostic cerebral angiography is usually unnecessary but can add to the understanding of the hemodynamics of the DVA, potential ruptured points, venous stenosis, and other associated pathologies such as dural AV shunts or AVM. In the present case, angiography was instrumental in confirming the diagnosis of thrombosed DVA, as well as excluding the possibility of an AVM or dural AV shunt.

In the vast majority of cases, DVAs are considered benign entities [8]. Under rare circumstances, they can cause symptoms such as headaches, seizures, focal neurological deficits, and dizziness for supratentorial lesions and gait disturbances and ataxia for infratentorial lesions $[1,2]$. Pereira et al. [2] reviewed all possible pathomechanisms of symptomatic DVAs, which are divided into mechanical and flow-related causes. Flow-related complications may result from increased inflow into the DVA (due to an AV shunt using the DVA as the drainage route) or decreased outflow of venous drainage. Outflow restriction may be due to an anatomic obstacle (stenosis or thrombosis of the DVA drainage, as in our case) or by a 'functional' obstacle due to a distant shunt/AVM overloading the venous system and hindering normal DVA drainage due to venous hypertension [2].

Drainage vein thrombosis of a DVA is rare, and only 28 patients with 29 cases of symptomatic thrombosed DVAs have been reported in the literature [1-9, 12-28]. These patients had a variety of presentations including venous ischemic infarction $(n=16,55 \%)$, parenchymal hemorrhage $(n=8,28 \%)$, venous congestive edema $(n=3,10 \%)$, or subarachnoid hemorrhage $(n=2,7 \%)$. Of these 29 cases, only 8 have been infratentorial [1-3, 5-9], and only 1 of those cases was due to venous congestion without subsequent venous infarction or hemorrhage (table 1). Thus, to the best of our knowledge, we present only the second case of an infratentorial thrombosed DVA causing venous congestive edema without concurrent infarction or hemorrhage.

Approximately two thirds of DVAs are supratentorial in location, and one third are located in the cerebellum and in the brainstem [1]. Thus a detailed knowledge of the venous anatomy of the posterior fossa is vital in understanding the pathomechanisms responsible for symptomatic infratentorial lesions. According to Lasjaunias et al. [29], the draining vessels of DVAs are preformed veins enlarged by additional blood flow. Lasjaunias et al. [30] describe the five common normal venular convergence patterns in the posterior fossa (precentral vein, vermian veins, cerebellar veins, petrosal vein confluence, transpontine vein). The metencephalon is drained by the petrosal vein, which is in turn primarily drained by the superior petrosal sinus. The collector vein of DVAs within the posterior fossa typically drains to a transpontine vein, precentral veins, the longitudinal intrategmental vein, or veins of the lateral recess of the fourth ventricle $[1,5]$. Kutscher et al. [31] shows that the petrosal vein confluent/ posterolateral recess convergence pattern is the most common of the five drainage patterns of posterior fossa DVAs described by Lasjaunias et al. [31]. Our patient demonstrated a DVA with a drainage pattern involving the petrosal vein confluent which opened into the vein of the lateral recess and subsequently the superior petrosal sinus. Thrombosis of this metencephalonic collection system subsequently caused venous congestive edema of the pons and the involved cerebellum.

Our patient was fortunate enough to be an extremely rare case of an infratentorial thrombosed DVA which did not progress to infarct or hemorrhage, either of which could have had devastating consequences given the location of pathology. Possible explanations for this lack 
Amuluru et al.: Symptomatic Infratentorial Thrombosed Developmental Venous Anomaly: Case Report and Review of the Literature

of progression may be due to the patient's anatomic redundancy of venous drainage of the left side of the pons, brachium pontis and cerebellum, which limited the severity of venous congestion. It is also possible that treatment was initiated early enough to prevent subsequent impending infarction and/or hemorrhage, which would underlie the importance of early diagnosis.

The absence of a smooth muscle layer and elastic lamina of DVA collector veins limits capacity for regulation and adaptation, which may result in hemodynamic disturbances predisposing DVAs to thrombosis [9]. Anatomic restriction of DVA outflow can produce a variety of presentations including venous congestive edema, hemorrhagic or venous infarction, similar to sinus and cortical venous thrombosis. Accordingly, many authors recommended that thrombosed DVAs be approached with the same workup and treatment regimen as cerebral venous thrombosis (CVT) [2, 32]. Although treatment with glucocorticoids may not be indicated in CVT, especially in the absence of parenchymal lesions, glucocorticoids are effective in reducing vasogenic edema [33]. Indeed, our patient's symptoms responded quickly to high-dose glucocorticoids within only a few days.

Treatment of CVT also involves the use of anticoagulation in order to prevent additional thrombi, enable recanalization, and avoid further growth of the thrombus [34, 35]. Similarly, anticoagulation therapy for thrombosed DVAs has been successfully reported in several cases involving venous congestion of a DVA, and even those in which venous infarction or congestive hemorrhage has occurred $[5,9,13,23,24,27]$. The decision to use anticoagulation in patients with symptomatic thrombosed DVAs must be preceded by an in-depth evaluation of additional hemorrhagic risk. The hemorrhagic risk associated with DVAs is very low, approximately $0.22-0.68 \%$ per year $[36,37]$, except for DVAs in the posterior fossa or during pregnancy $[1,38]$. However, in cases of hemorrhage related to DVAs, cavernous malformations are the most often encountered etiology [2,39]. Cavernous malformations are associated with DVAs in $13-40 \%$ of cases [34, 40]. Because of this frequent association, cavernous malformations should be specifically sought for using hemosiderin or deoxyhemoglobinsensitive sequences such as SWI, proton-density or T2-weighted sequences [7, 40]. In our case, the absence of cavernous malformation and hemorrhagic risk validated the safety of anticoagulation. Indeed, after 8 weeks of anticoagulation, our patient's symptoms completely resolved and there was complete resolution of all MR imaging abnormalities.

In addition to medical management, surgery in patients with a symptomatic DVA is indicated only when the patient presents with an extensive intracerebral hematoma $[1,41]$. In cases where a compressive brain hematoma or edema requires surgical management, particular care must be taken to preserve the DVA collecting vein to avoid catastrophic venous infarction [34]. Similarly, radiosurgery remains contraindicated because these DVAs drain normal brain parenchyma $[1,39]$.

The presented case of an infratentorial thrombosed DVA with cerebellar and pontine venous congestive edema is extremely rare. A working knowledge of posterior fossa venous anatomy and possible pathomechansims responsible for the rarely symptomatic lesion will aid in the timely and efficacious treatment of such lesions.

\section{Disclosure Statement}

All the authors involved have no conflicts of interest to disclose. 
Amuluru et al.: Symptomatic Infratentorial Thrombosed Developmental Venous Anomaly: Case Report and Review of the Literature

\section{References}

1 Peltier J, et al: Cerebral venous angioma of the pons complicated by nonhemorrhagic infarction. Case report. J Neurosurg 2004;101:690-693.

2 Pereira VM, et al: Pathomechanisms of symptomatic developmental venous anomalies. Stroke 2008;39:32013215.

3 Guerrero AL, et al: Venous infarct as presenting form of venous angioma of the posterior fossa (in Spanish) Rev Clin Esp 1998;198:484-485.

4 Brasse G, et al: Thrombosis of developmental venous anomaly and consecutive venous infarction (in German). Nervenarzt 2008;79:703-705.

5 Konan AV, et al: Cerebellar infarct caused by spontaneous thrombosis of a developmental venous anomaly of the posterior fossa. AJNR Am J Neuroradiol 1999;20:256-258.

6 Lovrencic-Huzjan A, et al: Subarachnoid haemorrhage headache from a developmental venous anomaly. Cephalalgia 2004;24:763-766.

7 Agarwal A, et al: Spontaneous thrombosis of developmental venous anomaly (DVA) with venous infarct and acute cerebellar ataxia. Emerg Radiol 2014;21:427-430.

8 Kiroglu Y, et al: Thrombosis of a drainage vein in developmental venous anomaly (DVA) leading venous infarction: a case report and review of the literature. J Neuroimaging 2011;21:197-201.

9 Griffiths D, et al: Thrombosis of a developmental venous anomaly causing venous infarction and pontine hemorrhage. J Stroke Cerebrovasc Dis 2013;22:e653-e655.

10 Blackmore CC, Mamourian AC: Aqueduct compression from venous angioma: MR findings. AJNR Am J Neuroradiol 1996;17:458-460.

11 Zouaoui A, et al: Modern imaging in cerebral vein angioma (in French). J Neuroradiol 1995;22:86-102.

12 Agazzi S, et al: Developmental venous anomaly with an arteriovenous shunt and a thrombotic complication. Case report. J Neurosurg 2001;94:533-537.

13 Flacke S, Stüer C, Stoffel M, Urbach H: Symptomatic developmental venous anomaly after spontaneous thrombosis of the collector vein. Clin Neuroradiol 2006;16:131-133.

14 Seki Y, Sahara Y: Spontaneous thrombosis of a venous malformation leading to intracerebral hemorrhage case report. Neurol Med Chir (Tokyo) 2007;47:310-313.

15 Hammoud D, et al: Ischemic complication of a cerebral developmental venous anomaly: case report and review of the literature. J Comput Assist Tomogr 2002;26:633-636.

16 Vieira Santos A, Saraiva P: Spontaneous isolated non-haemorrhagic thrombosis in a child with development venous anomaly: case report and review of the literature. Childs Nerv Syst 2006;22:1631-1633.

17 Amemiya S, Aoki S, Takao H: Venous congestion associated with developmental venous anomaly: findings on susceptibility weighted imaging. J Magn Reson Imaging 2008;28:1506-1509.

18 Walsh M, et al: Developmental venous anomaly with symptomatic thrombosis of the draining vein. J Neurosurg 2008;109:1119-1122.

19 Yamamoto $\mathrm{M}$, et al: Intracerebral hemorrhage due to venous thrombosis in venous angioma - case report. Neurol Med Chir (Tokyo) 1989;29:1044-1046.

20 Herbreteau O, et al: Symptomatic venous angioma. Report of a case (in French). J Neuroradiol 1999;26:126131.

21 Gama RL, et al: Thrombosed developmental venous anomaly associated with cerebral venous infarct. Arq Neuropsiquiatr 2008;66:560-562.

22 Masson C, et al: Cerebral venous infarction following thrombosis of the draining vein of a venous angioma (developmental abnormality). Cerebrovasc Dis 2000;10:235-238.

23 Thobois S, et al: Cortical thrombophlebitis and developmental venous anomalies (in French). Rev Neurol (Paris) 1999;155:48-50.

24 Merten CL, et al: Intracerebral haemorrhage from a venous angioma following thrombosis of a draining vein. Neuroradiology 1998;40:15-18.

25 Kim P, Castellani R, Tresser N: Cerebral venous malformation complicated by spontaneous thrombosis. Childs Nerv Syst 1996;12:172-175.

26 Field LR, Russell EJ: Spontaneous hemorrhage from a cerebral venous malformation related to thrombosis of the central draining vein: demonstration with angiography and serial MR. AJNR Am J Neuroradiol 1995;16: 1885-1888.

27 Bouchacourt E, et al: Ischemic accident caused by thrombosis of a venous angioma. Apropos of a case (in French). J Radiol 1986;67:631-635.

28 Lai PH, et al: Venous infarction from a venous angioma occurring after thrombosis of a drainage vein. AJR Am J Roentgenol 1999;172:1698-1699.

29 Lasjaunias P, Burrows P, Planet C: Developmental venous anomalies (DVA): the so-called venous angioma. Neurosurg Rev 1986; 9:233-242.

30 Lasjaunias P, Berenstein A, Ter Brugge KG: Intracranial venous system; in Lasjaunias P, Berenstein A (eds): Surgical Neuroangiography: Functional Vascular Anatomy of Brain, Spinal Cord and Spine. Springer, New York, 1990, p 688.

31 Kutscher ML, et al: Venous malformation mimicking a posterior fossa tumor in a young child. Pediatr Neurosci 1987;13:27-31. 
32 Haage P, Krings T, Schmitz-Rode T: Nontraumatic vascular emergencies: imaging and intervention in acute venous occlusion. Eur Radiol 2002;12:2627-2643.

33 Canhao P, et al: Are steroids useful to treat cerebral venous thrombosis? Stroke 2008;39:105-110.

34 Ruiz DS, Yilmaz H, Gailloud P: Cerebral developmental venous anomalies: current concepts. Ann Neurol 2009; 66:271-283.

35 Saposnik G, et al: Diagnosis and management of cerebral venous thrombosis: a statement for healthcare professionals from the American Heart Association/American Stroke Association. Stroke 2011;42:11581192.

36 Garner TB, et al: The natural history of intracranial venous angiomas. J Neurosurg 1991;75:715-722.

37 McLaughlin MR, et al: The prospective natural history of cerebral venous malformations. Neurosurgery 1998; 43:195-200; discussion 200-201.

38 Malik GM, et al: Venous angiomas: an underestimated cause of intracranial hemorrhage. Surg Neurol 1988;30: 350-358.

39 Topper R, et al: Clinical significance of intracranial developmental venous anomalies. J Neurol Neurosurg Psychiatry 1999;67:234-238.

40 Kuker W, Mull M, Thron A: Developmental venous anomalies of the posterior fossa with transpontine drainage: report of 3 cases. Eur Radiol 1997;7:913-917.

41 Nishizaki T, et al: Consideration of the operative indications for posterior fossa venous angiomas. Surg Neurol 1986;25:441-445. 